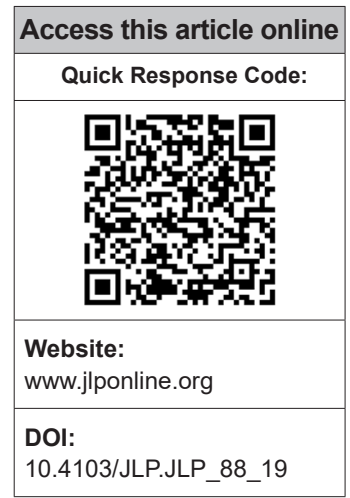

DOI:

10.4103/JLP.JLP_88_19
Department of Microbiology, VMMC Safdarjung Hospital,

Departments of

Microbiology and

${ }^{2}$ Radiotherapy, Biomedical Waste Unit, VMMC and

Safdarjung Hospital, New Delhi, India

Address for correspondence:

Dr. Malini Rajinder Capoor, Department of Microbiology, Biomedical Waste Unit, VMMC and Safdarjung Hospital, New Delhi - 110 029, India. E-mail: malinircapoor@ gmail.com

Submission: 21-05-2019 Accepted: 12-11-2019

\title{
Knowledge, attitude, and practices of Bio-medical Waste Management rules, 2016; Bio-medical Waste Management (amendment) rules, 2018; and Solid Waste Rules, 2016, among health-care workers in a tertiary care setup
}

\author{
Annapurna Parida, Malini Rajinder Capoor ${ }^{1}$, Kumar Tapas Bhowmik ${ }^{2}$
}

\section{Abstract:}

INTRODUCTION: Biomedical waste poses physical, chemical, radiological, and microbiological risks to the public and health-care workers (HCWs) for current and future generations.

AIM: The aim was to gauge the depth of understanding amongst HCWs on biomedical waste management (BMWM).

MATERIALS AND METHODS: A predesigned questionnaire on knowledge, attitude, and practices on BMWM Rules, 2016 (Principle), and 2018 (Amendment), Solid Waste Rules, 2016, and health hazards in HCW was distributed to all participants.

RESULTS: Only $68 \%$ of the participants knew that the most important step in waste management is waste segregation. Eighty-two percent of the HCWs working in this setup knew of the different color-coded bins used for segregation. However, awareness was lacking with respect to health hazards associated with improperly segregated and disposed off biomedical waste as only $49 \%$ answered the questions on the hazards of waste correctly. Laboratory waste handling was found to be the least understood area of the newer guidelines.

CONCLUSIONS: Training aspects of health-care waste management should be strengthened so that the current, existing, and future regulations are practiced diligently and uniformly. Periodic evaluation and assessment should become routine to enforce adherence to waste management.

Key words:

Biomedical waste management, Bio-medical Waste Management Rules 2016 and 2018, health-care workers, India

\section{Introduction}

Biomedical waste is any waste, which $\mathrm{B}$ is generated during the diagnosis,

This is an open access journal, and articles are distributed under the terms of the Creative Commons Attribution-NonCommercial-ShareAlike 4.0 License, which allows others to remix, tweak, and build upon the work non-commercially, as long as appropriate credit is given and the new creations are licensed under the identical terms.

For reprints contact: reprints@medknow.com treatment, or immunization of human beings or animals or in research activities pertaining thereto or in the production or testing of biologicals or in health camps: categories in Schedule I appended to Bio-medical

\footnotetext{
How to cite this article: Parida A, Capoor MR, Bhowmik KT. Knowledge, attitude, and practices of Bio-medical Waste Management rules, 2016; Bio-medical Waste Management (amendment) rules, 2018; and Solid Waste Rules, 2016, among healthcare workers in a tertiary care setup. J Lab Physicians 2019;11:292-9.
} 
Waste Management (BMWM) Rules, 2016. ${ }^{[1,2]}$ Improper management of medical waste has posed a grave threat not only to human health and safety but also to the environment for the current and future generations. ${ }^{[3]}$

Hospital waste is $85 \%$ noninfectious and only $15 \%$ infectious. ${ }^{[3]}$ However, poor segregation can cause the mixing of noninfectious with infectious waste and increase the total hazardous waste volume. In 2015, the Central Pollution Control Board, India, has estimated that 169,913 health-care facilities (HCFs) of India have generated approximately 495.30 tons / day biomedical waste, which roughly translates into $0.5-2 \mathrm{~kg} /$ bed/day. ${ }^{[4,5]}$ With newer complicated diagnostic and treatment modalities getting introduced every day, this volume has shown only an increasing trend. Previous methods of waste management such as the landfill and incineration are now ineffective in tackling this huge volume. Sometimes, incineration and landfill themselves pose a threat to the environment and population. This forced developers and regulators to change their focus from incineration and landfill to segregation, recycling, and waste minimization. ${ }^{[2,6]}$

The first regulation for efficient management of biomedical waste in India came in 1998. However, medical sciences transform faster than the methods of waste management methods. The most comprehensive and effective guidelines of waste management were introduced by the Government of India as BMWM (Principle) rules, 2016, and BMWM (amendment) rules, 2018..$^{[3,7]}$ These guidelines included a severe penalty as a deterrent to defaulters. Waste management guidelines now follow the cradle-to-grave approach and include all steps of waste generation, collection, storage, transportation, treatment, and ultimate destination (incineration, recycle). ${ }^{[8]}$

The International Clinical Epidemiology Network performed a nationwide survey in 25 districts across twenty states. Improper pretreatment of BMW at source and improper terminal disposal and lack of proper dedicated infrastructure were observed as the major challenges. ${ }^{[9]}$ Although numerous studies on the knowledge, attitude, and practices (KAP) of BMW rules, 1998, exist, studies on BMWM Rules, 2016, and BMWM (Amendment) Rules, 2018, are scarce. ${ }^{[10-20]}$ Just teaching about the rules without assessing the depth of understanding has led to a lot of mishaps related to biomedical waste. This study was done to test the KAP of BMWM (Principle) Rule, 2016, and BMWM (Amendment) Rule, 2018, and Solid Waste (SW) rules, 2016, among health-care workers (HCWs) in a tertiary care setup.

\section{Materials and Methods}

This study was undertaken in a 2873-bedded largest public sector hospital in New Delhi from April 2018 to September 2018. We have an established system of the mandatory teaching program of BMWM and SW Management for new HCWs, be it a doctor or housekeeping staff at the time of induction and once every year thereafter. The training program was conducted for $2 \mathrm{~h}$ for each session. It included lectures, open discussions, and demonstrations on all aspects of BMWM.

An in-house survey pertaining to health-care waste (BMW and SW) was planned to assess the existing knowledge and practices of the HCWs taking part in these training sessions. ${ }^{[10,11]}$ A self-designed pretested questionnaire [Annexure 1] as in all other studies done in this contemporary time, was used. ${ }^{[5,12-14]}$ We critically felt that a universal tool should be developed for assessment to establish uniformity. Participation in the survey was purely voluntary and anonymous. Questions were close ended (multiple-choice based) and based on the KAP of BMWM. Responses were checked by one of the study conductors and discussed at the end of each session. To ensure the understandability of the questionnaire, a trial test comprising of five participants from each study population group was done before the actual study. ${ }^{[12]}$ The language of the questionnaire was adjusted for clear-cut understanding, following discussion with the trial groups (English mainly for all except sanitation staff $[n=109])$.

Analysis of the responses was done under groups as follows: (1) knowledge and attitude (12 questions) and (2) practice (8 questions). Groups under which knowledge and attitude were analyzed were (a) Legal aspect and administration, (b) SW disposal, (c) color coding of disposal bins, (d) methods of sterilization and disinfection, and (e) health hazards, prevention, and management.

\section{Results}

A total of 1668 personnel attended the training program during the study period. As participation was voluntary, many choose not to take part, and only 1212 completed forms could be collected at the end. The collected responses were evaluated by the study supervisor while the training session was being conducted. At the end of each session, the checked responses were recirculated and discussed among the participants to increase comprehension. Out of the 1212 participants, $66 \%(n=799)$ were doctors of different specialties, $19 \%(n=230)$ were nurses, $6 \%(n=72)$ were laboratory 
technicians, and the rest $9 \%(n=109)$ were housekeeping staff [Figure 1].

Analysis of the compiled results showed that doctors and nurses were aware of the waste management rules and guidelines [Table 1]. Even though our hospital has a well-developed BMWM system in place, the knowledge among housekeeping staff was found to be lacking [Table 2]. Cronbach's alpha for the result was calculated to be $\geq 9$.

It was found that $68 \%$ of the participants knew it was necessary to segregate infectious from noninfectious waste. This leaves a staggering $32 \%$ of health-care personnel unaware of the problem. Knowledge of

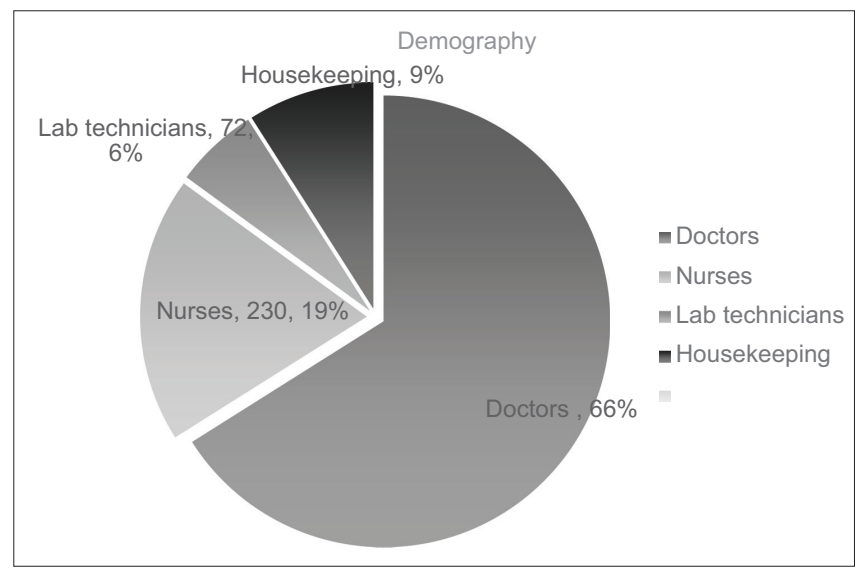

Figure 1: Demography of study population color-coded bins used in our facility was good among all groups except the housekeeping staff, of whom only $56 \%$ answered this question correctly [Table 1].

\section{Discussion}

At present times, focus has shifted to the reduction of infectious waste volume. This reduction can be achieved by first separating infectious waste from noninfectious waste. Similar to the study by Bhagawati et al., 2015, in this study, $68 \%$ of the participants knew that the key step is segregation, but $32 \%$ of all HCWs did not know how to differentiate infectious from noninfectious waste. ${ }^{[15]}$ On simplification, only $41 \%$ of the housekeeping staff could tell the proper color coding of waste, as was the case with Mathur et al., 2011 (27\%), and Soyam et al., 2017 (25\%), and Bansal et al., 2011 (43\%). ${ }^{[5,16,17]}$ The most worrying point was nearly half of the HCW population is unaware of the prerequisite of treatment of laboratory waste before sending out of the facility. Even in the case of laboratory technicians, $70 \%$ answered this question correctly.

Doctors, nurses, and laboratory technicians were well versed with waste segregation, color coding, and the important health hazards of biomedical waste. Our finding agrees with that of Mathur et al., 2011, that the lack of formal education among the house-keeping staff might play a factor in low awareness among them. ${ }^{[5]}$ Another problem in the color coding system arises for

Table 1: Knowledge and attitude among health-care workers about Bio-Medical Waste Management rules, 2016 and 2018, and Solid Waste rules, 2016

\begin{tabular}{|c|c|c|c|c|c|}
\hline Knowledge and attitude & Doctors $(n=799)$ & Nurses $(n=230)$ & Laboratory technician ( $n=72)$ & Housekeeping staff ( $n=109)$ & Total $(n=1212)$ \\
\hline $\begin{array}{l}\text { Legal aspect and } \\
\text { administration (\%) }\end{array}$ & 73 & 67 & 61 & 63 & 70 \\
\hline Solid waste disposal (\%) & 76 & 89 & 74 & 44 & 74 \\
\hline $\begin{array}{l}\text { Color coding of disposal } \\
\text { bins }(\%)\end{array}$ & 84 & 88 & 78 & 56 & 82 \\
\hline $\begin{array}{l}\text { Methods of sterilization and } \\
\text { disinfection (\%) }\end{array}$ & 79 & 73 & 77 & 70 & 77 \\
\hline $\begin{array}{l}\text { Health hazards, prevention, } \\
\text { and management }(\%)\end{array}$ & 49 & 58 & 57 & 24 & 49 \\
\hline
\end{tabular}

Cronbach's $\alpha-0.9375$

Table 2: Practices among health-care workers about Bio Medical Waste Management rules, 2016 and 2018, and Solid Waste rules, 2016

\begin{tabular}{lccccc}
\hline Practices & Doctors $(n=799)$ & Nurses $(n=230)$ & Laboratory technician $(n=72)$ & Housekeeping staff $(n=109)$ & Total $(n=1212)$ \\
\hline $\begin{array}{l}\text { Differentiating infectious from } \\
\text { noninfectious waste (\%) }\end{array}$ & 73 & 65 & 63 & 41 & 0.1 \\
$\begin{array}{l}\text { Treatment of laboratory } \\
\text { waste before discarding (\%) }\end{array}$ & 45 & 52 & 70 & 36 & 45 \\
$\begin{array}{l}\text { Reporting of sharp-related } \\
\text { injury (\%) }\end{array}$ & 77 & 67 & 27 & 69 & 12 \\
$\begin{array}{l}\text { Hepatitis B vaccination (\%) } \\
\text { Hand hygiene (\%) }\end{array}$ & 66 & 75 & 40 & 31 & 63 \\
\hline
\end{tabular}

Cronbach's $\alpha-0.9375$ 
the general waste (SW), where blue bags are used. In this study, $89 \%$ of the nurses answered correctly, whereas only $44 \%$ of the housekeeping staff were able to answer correctly. No previous study was found regarding SW disposal and compliance in HCWs. The authors strongly feel that every biomedical waste training curriculum should include SW/general waste management.

Only $36 \%$ of the housekeeping staff knew what to do after needlestick injury. Other studies which were conducted earlier have also shown a similar finding. Laboratory technicians were poorly aware of how to manage sharp injury (27\%) and adhering to the principles of hygiene (40\%), which was abysmal compared to the study by Dudi et al., 2016, but somewhat agrees with the finding of Ismail et al., 2013. ${ }^{[14,18]}$ Anyone working in the health sector, that comes in contact with infectious material daily, must have adequate knowledge of health-care waste management. Anything less than absolute perfect knowledge is a disaster waiting to happen.

Numerous studies on the KAPs of BMW rules, $1998^{\text {[10-19] }}$ were done, but studies on KAP for BMWM Rules, 2016, and BMWM (Amendment) Rules, 2018, compliance, are scarce. ${ }^{[20]}$ In this study, even though doctors knew the importance of health-care waste management, when it comes to guidelines, their knowledge is not complete [Table 1]. Other HCWs were better in working knowledge as on an average, $\geq 70 \%$ could answer the methods of disinfection and sterilization. The gravity of this issue just cannot be ignored. To increase awareness, the curriculum of medical, postgraduate, nursing, laboratory technology, and other paramedical courses should give higher importance on biomedical waste, its hazards, and its impact on the society.

The limitation of our study was that the study population was positively skewed in favor of doctors followed by nurses. Although a large population of housekeeping staff took part in the training for BMWM, only $\leq 30 \%$ took part in the study. Housekeeping staff who handle and transport waste should undergo repeated training and evaluation, as their attrition rate is high in HCFs.

\section{Conclusions}

It is concluded that repeated and comprehensive training (starting with induction of all new appointees to once a year thereafter) by vertical and horizontal modes on BMWM is the only way forward. Mandatory attendance in regular training programs and periodic assessments should be included in yearly performance assessment of all HCWs to increase compliance. The spirit of BMWM rules is dynamic, and it is reinforced by the fact that by the time we penned down our study,
BMWM rules, 2019, have been already rolled out twice in 2019. ${ }^{[21]}$

\section{Financial support and sponsorship \\ Nil.}

\section{Conflicts of interest}

There are no conflicts of interest.

\section{References}

1. The Gazette of India Biomedical Wastes (Management and Handling) Rules, India: Ministry of Environment and Forests, Government of India; 20 July, 1998.

2. Capoor MR, Bhowmik KT. Implementation challenges in Bio-medical Waste Management rules, 2016. Indian J Med Microbiol 2017;35:623-5.

3. Chartier Y, Emmanuel J, Pieper U, Prüss A, Rushbrook P, Stringer R. Safe Management of Wastes from Health-Care Activities. $2^{\text {nd }}$ ed. Geneva, Switzerland: WHO Blue Book; 2014.

4. Central Pollution Control Board, Waste Management DivisionBio-Medical Waste. Status on Bio-medical Waste Management scenario and recommendations for ensuring compliance to the Bio-Medical Waste Management Rules, 2016. p. 3.

5. Mathur V, Dwivedi S, Hassan M, Misra R. Knowledge, attitude, and practices about biomedical waste management among healthcare personnel: A cross-sectional study. Indian J Community Med 2011;36:143-5.

6. Patil GV, Pokhrel K. Biomedical solid waste management in an Indian hospital: A case study. Waste Manag 2005;25:592-9.

7. Ministry Of Environment. Bio-Medical Waste Management (Amendment) Rules, 2018. Forest And Climate Change Notification New Delhi; 2018.

8. Capoor MR, Bhowmik KT. Current perspectives on Bio-medical Waste Management: Rules, conventions and treatment technologies. Indian J Med Microbiol 2017;35:157-64.

9. INCLEN Program Evaluation Network (IPEN) study group, New Delhi, India. Bio-medical waste management: Situational analysis and predictors of performances in 25 districts across 20 Indian states. Indian J Med Res 2014;139:141-53.

10. Nema A, Pathak A, Bajaj P, Singh H, Kumar S. A case study: Biomedical waste management practices at city hospital in Himachal Pradesh. Waste Manag Res 2011;29:669-73.

11. Yadavannavar M, Berad AS, Jagirdar P. Biomedical waste management: A study of knowledge, attitude, and practices in a tertiary health care institution in Bijapur. Indian J Community Med 2010;35:170-1.

12. Anand P, Jain R, Dhyani A. Knowledge, attitude and practice of biomedical waste management among health care personnel in a teaching institution in Haryana, India. Int J Res Med Sci 2016;4:4246-50.

13. Sengodan V, Amruth K. Knowledge attitude and practice study on biomedical waste management among health care professionals and paramedical students in a tertiary care Government hospital in South India. Int J Environ Health Eng 2014;3:11.

14. Dudi M, Sharma R, Sharma S, Jain M. Assessment of the knowledge, attitude, and practices regarding biomedical waste management amongst paramedical staff in a tertiary level health care facility. Int J Med Sci Public Health 2016;5:615-9.

15. Bhagawati G, Nandwani S, Singhal S. Awareness and practices regarding bio-medical waste management among health care workers in a tertiary care hospital in Delhi. Indian J Med Microbiol 2015;33:580-2.

16. Soyam GC, Hiwarkar PA, Kawalkar UG, Soyam VC, Gupta VK. 
KAP study of bio-medical waste management among health care workers in Delhi. Int J Community Med Public Health 2017;4:3332-7.

17. Bansal M, Mishra A, Gautam P, Changulani R, Srivastava D, Gour NS. Biomedical waste Management: Awareness and practices in a district of Madhya Pradesh. Natl J Community Med 2011;2:452-6.

18. Ismail IM, Kulkarni AG, Kamble SV, Borker SA, Rekha R, Amruth $\mathrm{M}$. Knowledge, attitude and practice about bio-medical waste management among personnel of a tertiary health care institute in Dakshina Kannada, Karnataka. Al Ameen J Med Sci 2013;6:376-80.
19. Joseph L, Paul H, Premkumar J, Rabindranath, Paul R, Michael JS, et al. Biomedical waste management: Study on the awareness and practice among healthcare workers in a tertiary teaching hospital. Indian J Med Microbiol 2015;33:129-31.

20. Bhattar S, Qureshi S, Seth R, Butola R, Shingare P. Awareness and practices of biomedical waste management guidelines 2016 in an upcoming super speciality hospital of east Delhi, India. International Journal Of Community Medicine And Public Health 2018;5:3289-3292.

21. Ministry of Environment. Bio-Medical Waste Management (Amendment) Rules 2019. Forest And Climate Change Notification New Delhi; 2019. 